\title{
Development of a New Heterogeneous Lewis Acid Catalyst for Chemoselective Tetrahydropyranylation of Different Hydroxyl Compounds
}

\author{
Majid Kolahdoozan ${ }^{1,2}$ and Mahshid Hossaini' \\ ${ }^{1}$ Department of Chemistry, Islamic Azad University, Shahreza Branch, Shahreza, Isfahan 311-86145, Iran \\ ${ }^{2}$ Young Researcher Club, Islamic Azad University, Shahreza Branch, Shahreza, Isfahan 311-86145, Iran \\ Correspondence should be addressed to Majid Kolahdoozan; kolahdoozan@iaush.ac.ir
}

Received 28 June 2012; Revised 19 August 2012; Accepted 3 September 2012

Academic Editor: Antonia Chiou

Copyright (C) 2013 M. Kolahdoozan and M. Hossaini. This is an open access article distributed under the Creative Commons Attribution License, which permits unrestricted use, distribution, and reproduction in any medium, provided the original work is properly cited.

\begin{abstract}
Amino functionalized triazine supported on silica-gel was prepared and characterized. This new triazine derivative was applied as a coordinating agent for aluminum chloride. This novel Lewis acid supported on heterogeneous surface was used as an effective catalyst for protection of alcohols and phenols in the presence of 3,4-dihydro-2H-pyran. This catalyst can be reused without any significant loss of activity, and it protects alcohols in the presence of phenols.
\end{abstract}

\section{Introduction}

Contemporary organic synthesis faces the challenge of developing new, efficient, atom, economical, and ecofriendly processes that enable the preparation of diverse structures in a rapid and cost-effective manner. According to the principles of Green Chemistry, catalytic reagents (as selective as possible) are superior to stoichiometric reagents. In general, catalysts reduce the amount of reagents required and restrict the waste generated in a reaction. They reduce energy requirements and decrease the number of separation steps due to increased selectivity [1-3].

Utilization of heterogeneous catalyst fulfills some of the Green Chemistry criteria $[4,5]$. Of these, enhanced stability, higher selectivity, easier handling, simple workup procedures, nontoxicity, noncorrosiveness, mildness of the reaction conditions, ease of recovery, and reuse of the catalyst and the most important is that it can protects the water-sensitive Lewis acids from hydrolysis by atmospheric moisture until it is suspended in an appropriate solvent, where it can be used in a chemical reaction [5].

The protection of hydroxyl group in alcohols and phenols is a common and versatile event in multistep organic synthesis. Several methods such as acetylation [6, 7], trimethylsilylation [8,9], methoxymethylation [10], and tetrahydropyranylation have been developed for masking hydroxyl groups. Amongst them, tetrahydropyranylation is the most frequently used method because of its low cost, ease of preparation, and ease of removing protecting groups as well as the remarkable stability of tetrahydropyranyl ethers under a variety of conditions such as Grignard reagents, alkyl lithiums, oxidative reagents, and acylating reagents $[11,12]$. A variety of catalysts that have been reported for this conversion include the use of LiOTf [13], Pyridinium $p$-toluenesulfonate[14], silicasulphuric acid [15], $\mathrm{SiO}_{2}-\mathrm{AlCl}_{3}$ [16], polystyrene- $\mathrm{AlCl}_{3}$ [17], $\mathrm{CeCl}_{3} \cdot 7 \mathrm{H}_{2} \mathrm{O} / \mathrm{NaI}$ [18], copper nitrate/acetic acid [19], heteropolyacids [20], and 1-alkyl-3methylimidazolium tetrachloroindate under microwave irradiation [21]. Although these methods are suitable, many of them are associated with several drawbacks, which include long reaction time, high cost, harsh and acidic conditions, poor selectivity, formation of polymeric by-products of the dihydropyran, and isomerization. Furthermore, some of these catalysts may affect other existing functional of molecules, and some are not recyclable and require tedious workup of the reaction mixture. 
Combination of these features would be desirable to arrive at an ideal catalyst system. Here, the catalyst was prepared via modification of silica surface by aminated triazine ring followed by $\mathrm{AlCl}_{3}$ loading. This catalyst can be used as a mild, efficient, and high chemoselective heterogeneous catalyst for tetrahydropyranylation of various hydroxyl functions in alcohols and phenols.

\section{Experimental}

2.1. Materials and Solvents. The reagents and solvents were purchased from Merck, Fluka and Aldrich Chemical companies. The samples were analyzed by FT-IR spectroscopy (PerkinElmer Spectrum Version 65), and the aluminum content of the catalysts was estimated by atomic absorption spectrometer (AAS) (Perkin-Elmer, Analyst 300). Scanning electron microscope (SEM); studies were recorded on AIS2100, Korea microscope equipped with an energy dispersive $\mathrm{X}$-ray analyzer (EDX).

\subsection{Preparation of Aminated Triazine Supported on Silica-Gel} (AT-Silica). 1.2 g Silica gel (particle size 20-63 $\mu \mathrm{m}, 70-230$ mesh pore size $100 \AA$ ) and $10 \mathrm{~mL}$ dry tetrahydrofuran (THF) in a 25 round bottom flask were cooled in an ice bath. To this mixture triethylamine (TEA, $0.5 \mathrm{~mL}, 3.7 \mathrm{mmol}$ ) was added and stirred for $10 \mathrm{~min}$. Then cyanuric chloride $(1.2 \mathrm{~g}$, $6.5 \mathrm{mmol}$ ) was added and the mixture was stirred for $1 \mathrm{~h}$ in an ice bath and $2 \mathrm{~h}$ at room temperature. The solid was filtered, washed with dry THF, and dried at $60^{\circ} \mathrm{C}$ for $2 \mathrm{~h}$ to give $1.9 \mathrm{~g}$ of cyanuric chloride grafted on silica-gel (CCsilica). In the second step $1.5 \mathrm{~g}$ of CC-silica in $10 \mathrm{~mL}$ dry THF was reacted with $1.5 \mathrm{~mL}$ ethylenediamine (EDA) in the round bottom flask. The reaction mixture was stirred in an ice bath for $1 \mathrm{~h}$ and heated to room temperature, and then TEA ( $1 \mathrm{~mL})$ was added and stirred overnight. Finally, it was refluxed for $45 \mathrm{~min}$, and the solid was filtered to give $1.9 \mathrm{~g}$ aminated-triazine supported on silica-gel (AT-silica).

2.3. Coordination of $\mathrm{AlCl}_{3}$ on to AT-Silica. The new catalyst was prepared by refluxing the mixture of $1.2 \mathrm{~g}(8.9 \mathrm{mmoL})$ of anhydrous $\mathrm{AlCl}_{3}$, carbon tetrachloride $(3 \mathrm{~mL})$, and ATsilica $(1.0 \mathrm{~g})$ for $17 \mathrm{~h}$. The solid was filtered and washed with carbon tetrachloride three times, and then it was dried under vacuum for $3 \mathrm{~h}$ at $60^{\circ} \mathrm{C}$ to give $\mathrm{Al}^{3+}$ supported on AT-silica (Al/AT-silica). The aluminum content of Al/AT-silica was determined by atomic absorption method and was found to be $3.27 \mathrm{mmol} \mathrm{Al}^{3+}$ per gram of the catalyst.

2.4. Tetrahydropyranylation Reaction. Alcohol or phenol ( $1 \mathrm{mmol}$ ) was added to a mixture of 3,4-dihydro-2H-pyran $(1.2 \mathrm{mmol})$ and $\mathrm{Al} / \mathrm{AT}$-silica $(0.03 \mathrm{~g})$ in dichloromethane $\left(\mathrm{CH}_{2} \mathrm{Cl}_{2}, 0.5 \mathrm{~mL}\right)$. The mixture was stirred at $40^{\circ} \mathrm{C}$. The progress of the reaction was monitored by gas chromatography (GC) and thin layer chromatography (TLC). After completion of the reaction, the mixture was filtered, and the residue was washed with dichloromethane. The filtrate was concentrated on a rotary evaporator under reduced pressure to give the product. Further purification was achieved by
TABLE 1: The effect of solvent for tetrahydropyranylation of benzyl alcohol $^{\mathrm{a}}$.

\begin{tabular}{lccc}
\hline Entry & Solvent & Time $(\mathrm{min})$ & Yield $(\%)^{\mathrm{b}}$ \\
\hline 1 & toluene & 70 & 35 \\
2 & $n$-hexane & 60 & 53 \\
3 & acetone & 60 & 40 \\
4 & dioxane & 60 & 25 \\
5 & $\mathrm{THF}$ & 50 & 40 \\
6 & $\mathrm{CH}_{2} \mathrm{Cl}_{2}$ & 45 & 95 \\
\hline
\end{tabular}

${ }^{\mathrm{a}} 0.03 \mathrm{~g}$ catalyst, $1 \mathrm{mmol}$ benzyl alcohol, $1.2 \mathrm{mmol} \mathrm{DHP}$, and $T=40^{\circ} \mathrm{C}$.

${ }^{\mathrm{b}}$ Maximum conversion.

column chromatography (silica gel, eluant; hexane/ethyl acetate, $80 / 20$, v/v).

Tetrahydro-2-(phenylmethoxy)-2H-pyran (Table 2, Entry 1, [22, 23]): yield 95\%, ${ }^{1} \mathrm{H}-\mathrm{NMR}\left(400 \mathrm{MHz}, \mathrm{CDCl}_{3}\right.$, ppm): $\delta=7.24-7.41(5 \mathrm{H}, \mathrm{m}), 4.84(1 \mathrm{H}, \mathrm{d}, J=12 \mathrm{~Hz}), 4.77$ $(1 \mathrm{H}, \mathrm{t}), 4.55(1 \mathrm{H}, \mathrm{d}, J=12 \mathrm{~Hz}), 3.93-4.01(1 \mathrm{H}, \mathrm{m}), 3.56-3.63$ $(1 \mathrm{H}, \mathrm{m}), 1.53-1.98(6 \mathrm{H}, \mathrm{m})$. FT-IR $\left(\mathrm{KBr}, \mathrm{cm}^{-1}\right): 3031,2945$, 2854, 1498, 1453, 1351, 1262, 1125, 1027.

Tetrahydro-2-(4-nitrophenylmethoxy)-2H-pyran (Table 2, Entry 6, [23]): yield 95\%, ${ }^{1} \mathrm{H}-\mathrm{NMR}\left(400 \mathrm{MHz}, \mathrm{CDCl}_{3}\right.$, ppm): $\delta=8.22(2 \mathrm{H}, \mathrm{d}, J=8.4 \mathrm{~Hz}), 7.54(2 \mathrm{H}, \mathrm{d}, J=8.4 \mathrm{~Hz})$, $4.90(1 \mathrm{H}, \mathrm{d}, J=13.6 \mathrm{~Hz}), 4.75(1 \mathrm{H}, \mathrm{t}), 4.62(1 \mathrm{H}, \mathrm{d}, J=$ $13.6 \mathrm{~Hz}), 3.85-3.94(1 \mathrm{H}, \mathrm{m}), 3.54-3.61(1 \mathrm{H}, \mathrm{m}), 1.53-1.96$ $(6 \mathrm{H}, \mathrm{m})$. FT-IR $\left(\mathrm{KBr}, \mathrm{cm}^{-1}\right): 3078,2946,2853,1605,1521$, 1453, 1346, 1127, 1069, 1035.

Tetrahydro-2-(4-chlorophenylmethoxy)-2H-pyran (Table 2, Entry 2, [24]): yield 94\%, ${ }^{1} \mathrm{H}-\mathrm{NMR}(400 \mathrm{MHz}$, $\left.\mathrm{CDCl}_{3}, \mathrm{ppm}\right): \delta=7.45(2 \mathrm{H}, \mathrm{d}, J=8.8 \mathrm{~Hz}), 7.24(2 \mathrm{H}, \mathrm{d}$, $J=8.8 \mathrm{~Hz}), 4.71(1 \mathrm{H}, \mathrm{d}, J=12 \mathrm{~Hz}), 4.65-4.68(1 \mathrm{H}, \mathrm{m}), 4.46$ $(1 \mathrm{H}, \mathrm{d}, J=12 \mathrm{~Hz}), 3.84-3.90(1 \mathrm{H}, \mathrm{m}), 3.52-3.56(1 \mathrm{H}, \mathrm{m})$, $1.53-1.91(6 \mathrm{H}, \mathrm{m})$. FT-IR $\left(\mathrm{KBr}, \mathrm{cm}^{-1}\right): 3063,2954,2863$, 1589, 1458, 1353, 1129, 1071, 1037.

Tetrahydro-2-(cyclohexyl)-2H-pyran (Table 2, Entry 12, [25]): yield 91\%, ${ }^{1} \mathrm{H}-\mathrm{NMR}\left(400 \mathrm{MHz}, \mathrm{CDCl}_{3}, \mathrm{ppm}\right): \delta=4.70$ $(1 \mathrm{H}, \mathrm{t}, J=3.1 \mathrm{~Hz}), 3.88-3.97(1 \mathrm{H}, \mathrm{m}), 3.49-3.54(2 \mathrm{H}, \mathrm{m})$, 1.16-1.98 (16H, m). FT-IR (KBr, cm $\left.{ }^{-1}\right): 2938,1447,1352$, $1220,1175,1127,1071$

Tetrahydro-2-(phenoxy)-2H-pyran (Table 2, Entry 8, [25]): yield 95\%, ${ }^{1} \mathrm{H}-\mathrm{NMR}\left(400 \mathrm{MHz}, \mathrm{CDCl}_{3}, \mathrm{ppm}\right)$ : 6.95-7.40 (5H, m), $5.45(1 \mathrm{H}, \mathrm{m}), 3.89-3.98(1 \mathrm{H}, \mathrm{m})$, 3.55-3.67 (1H, m), 1.62-2.08 (6H, m). FT-IR $\left(\mathrm{KBr}, \mathrm{cm}^{-1}\right)$ : 3020, 2945, 1625, 1543, 1448, 1363, 1170, 1130, 1069.

\section{Results and Discussion}

Silica-gel surfaces were modified with an aliphatic amine (EDA) via a two-step chemical reaction. Cyanuric chloride was chemically bound with surface hydroxyl groups of silicagel followed by reaction with EDA (Scheme 1). This new triazine derivate was applied as a coordination agent for $\mathrm{AlCl}_{3}$ in carbon tetrachloride.

The structure of this catalyst was confirmed by FT-IR spectroscopy. The spectrum of silica-gel shows absorptions bands around $1103 \mathrm{~cm}^{-1}(\mathrm{Si}-\mathrm{O})$ and $3450 \mathrm{~cm}^{-1}(\mathrm{SiO}-\mathrm{H})$ 
TABLE 2: Tetrahydropyranylation of various alcohols and phenols ${ }^{\mathrm{a}}$.

\begin{tabular}{|c|c|c|c|c|}
\hline Entry & Hydroxy compound & Product & Time $(\min )^{\mathrm{b}}$ & Yield $(\%)^{c}$ \\
\hline 1 & & & 45 & 95 \\
\hline 2 & & & 55 & 94 \\
\hline 3 & & & 50 & 92 \\
\hline 4 & & & 60 & 95 \\
\hline 5 & & & 210 & 93 \\
\hline 6 & & & 120 & 93 \\
\hline 7 & & & 60 & 94 \\
\hline 8 & & & 45 & 95 \\
\hline 9 & & & 60 & 63 \\
\hline 10 & & & 120 & 50 \\
\hline 11 & & & 120 & 40 \\
\hline 12 & & & 60 & 91 \\
\hline 13 & & & 45 & 95 \\
\hline
\end{tabular}

$1 \mathrm{mmol}$ alcohol, $1.2 \mathrm{mmol} \mathrm{DHP,} 1 \mathrm{~mL} \mathrm{CH}_{2} \mathrm{Cl}_{2}$, and $T=40^{\circ} \mathrm{C}$.

${ }^{\mathrm{b}}$ Time of maximum conversion.

${ }^{\mathrm{c}}$ Isolated yield.

(Figure 1(a)). After reaction of silica-gel with cyanuric chloride, new peaks at $1721 \mathrm{~cm}^{-1}, 1477 \mathrm{~cm}^{-1}$, and $1590 \mathrm{~cm}^{-1}$ $(\mathrm{C}-\mathrm{Cl}, \mathrm{C}=\mathrm{N}$ stretching of triazine ring $)$ as well as existing bonds at 1103 to $1105 \mathrm{~cm}^{-1}$ appeared (Figure 1(b)). The
FT-IR spectrum of AT-silica (Figure 1(c)) displays a broad absorption (with two-week peaks) around $3300-3400 \mathrm{~cm}^{-1}$ (stretching $\mathrm{N}-\mathrm{H}$ ) and two peaks at 1495 and $1588 \mathrm{~cm}^{-1}$ (broad, $\mathrm{C}=\mathrm{N}$ stretching and $\mathrm{N}-\mathrm{H}$ vibration). 


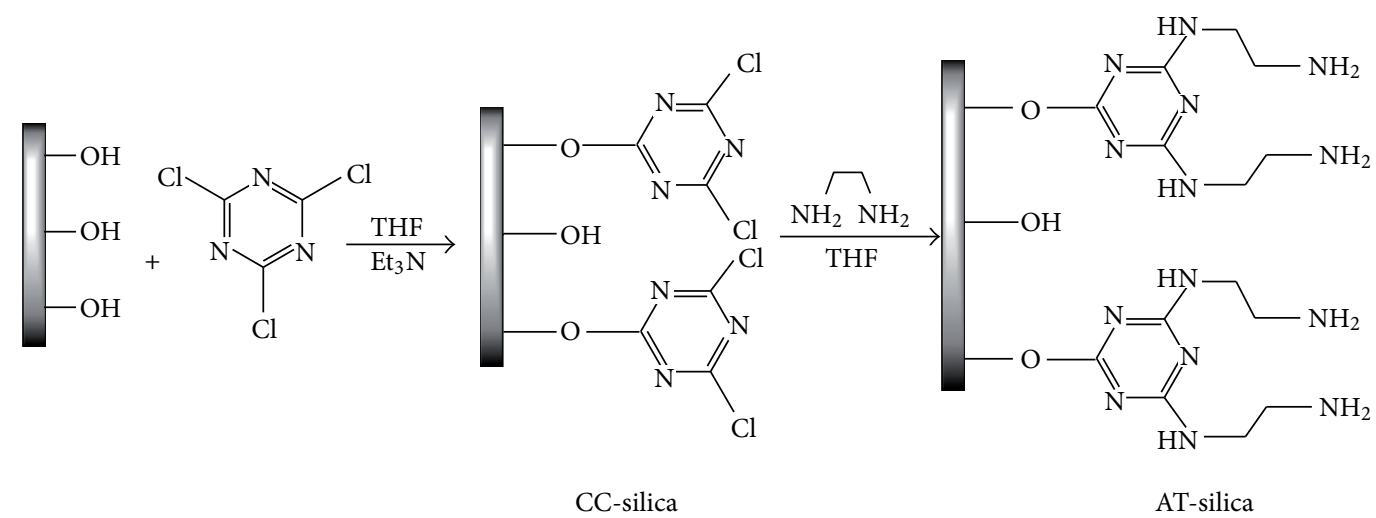

Scheme 1: Preparation of AT-silica.

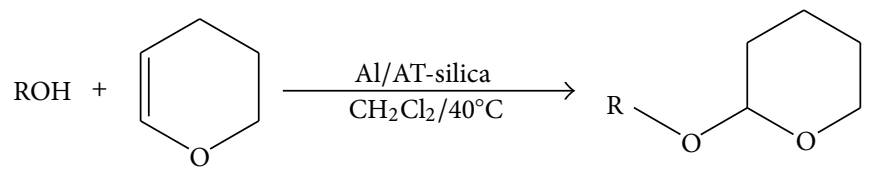

SCHEME 2: Tetrahydropyranylation of alcohols and phenols.

Figure 2 shows the SEM images of (a) AT-silica and (b) the immobilized aluminum on AT-silica (Al/AT-silica). Clear changes in the morphologies of the catalyst after introduction of metals were observed by SEM.

Comparisons of EDX analysis of AT-silica with Al/ATsilica confirmed addition of aluminum to the catalyst, which suggested the formation of metal complexes with the anchored ligand (Figure 3).

The catalytic activity of this new heterogeneous Lewis acid evaluated for the tetrahydropyranylation reaction of alcohols and phenols (Scheme 2).

Since the solvents play an important role for the catalytic activity of the Al/AT-silica catalyst, a variety of solvents such as toluene, $n$-hexane, acetone, dioxane, tetrahydrofuran, and dichloromethane were used for tetrahydropyranylation of benzyl alcohol as a model substrate (Table 1). The results show that dichloromethane as solvent give better result for tetrahydropyranylation of alcohols.

The amounts of catalyst, molar ratio of DHP to alcohol, reaction time, and temperature were also varied in order to monitor the progress of reaction. The various test reactions demonstrated that the best results for tetrahydropyranylation of $1 \mathrm{mmoL}$ benzyl alcohol were $0.03 \mathrm{~g}$ of the catalyst, $1.2 \mathrm{mmoL}$ of DHP in the presence of $\mathrm{CH}_{2} \mathrm{Cl}_{2}$ as a solvent at $40^{\circ} \mathrm{C}$. The results of the protection reactions of a diverse range of alcohols and phenols are collected in Table 2. Al/AT-silica can promote tetrahydropyranylation of primary, secondary, and benzylic alcohols, as well as phenols, in good to excellent yields. Primary benzylic alcohols with electron-donating and electron-withdrawing groups were tetrahydropyranylated in this catalyst, and the corresponding tetrahydropyranyl ethers were obtained in almost quantitative yields (Table 2, entries 1-7). The ability of Al/AT-silica was also investigated in the tetrahydropyranylation of phenol under the same reaction conditions described for alcohols, and the corresponding THP-ethers were obtained in high yields (Table 2, entry 8 ). The nitro derivatives of phenols (Table 2, entry 1011) produced the corresponding protected product in lower yield. The possible reason ascribed to this observation could be the electron-withdrawing effect of the nitro group. Tetrahydropyranylation of linear and saturated primary and secondary alcohols were also achieved in the presence of this catalyst in high yields.

The stability and reusability are the main advantages of this novel heterogeneous catalyst. The Al/AT-silica catalyst could be stored and used under open air conditions. Furthermore, the catalyst was quantitatively recovered by simple filtration and washing and proved to be reusable up to 4 times without appreciable loss of catalytic activity and selectivity (Figure 4).

In order to examine the chemoselectivity of the present method, equimolar mixtures of phenol and primary alcohols such as benzyl alcohol and hexanol were allowed to react with DHP in the presence of Al/AT-silica. Scheme 3 shows the conversion of alcohols or phenol to their corresponding THP-ether in compare with its starting hydroxy compounds. This scheme demonstrates that Al/AT-silica can discriminate between alcohols and phenol from each other in 


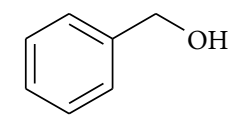

$1 \mathrm{mmol}+$

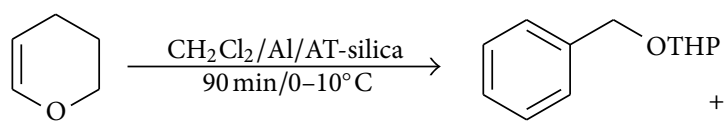<smiles>Oc1ccccc1</smiles>

$1.2 \mathrm{mmol}$

$92 \%$<smiles>Oc1ccccc1</smiles>

$10 \%$

$1 \mathrm{mmol}$<smiles>CCCCCCO</smiles><smiles>[AlH2][TeH]</smiles><smiles>ClCCOC1CCCO1</smiles><smiles>CCCCCC[OH+]</smiles><smiles>CCOc1ccccc1</smiles><smiles>Oc1ccccc1</smiles>

$1.2 \mathrm{mmol}$

$81 \%$

$12 \%$

$1 \mathrm{mmol}$

Scheme 3: Chemoselective tetrahydropyranylation of alcohols in the presence of phenols catalyzed by Al/AT-silica.

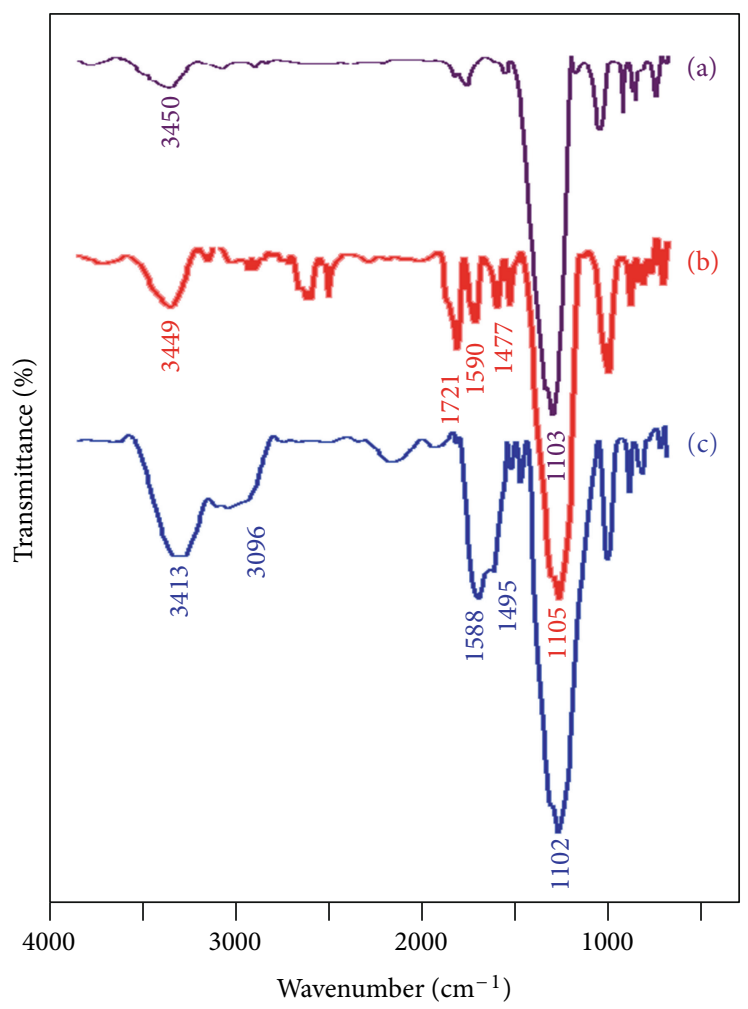

FIGURE 1: FT-IR Spectra of (a) silica gel, (b) CC-Silica, and (c) AT-Silica. 


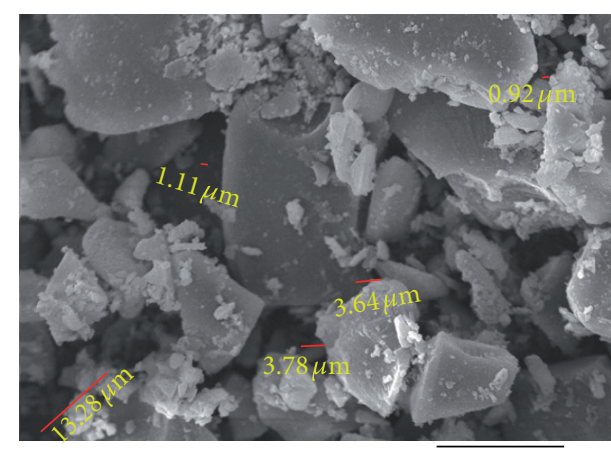

SEI $\quad \mathrm{WD}=8.5 \quad 20.00 \mathrm{kV} \quad \mathrm{x} 2.0 \mathrm{~K} \quad 30 \mu \mathrm{m}$

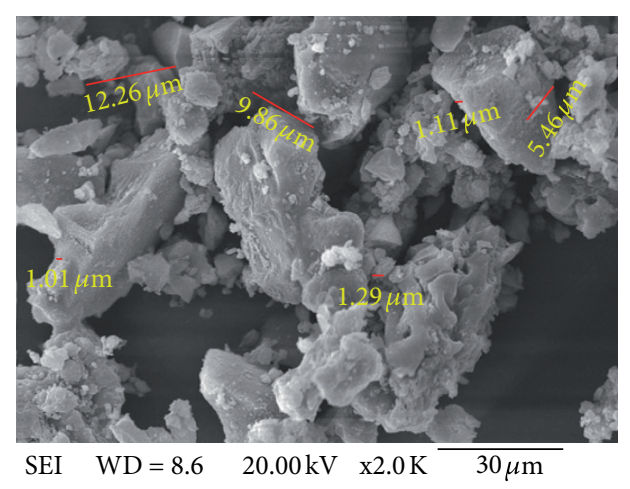

(b)

(a)

FIgURE 2: SEM images of (a) AT-silica and (b) Al/AT-silica.

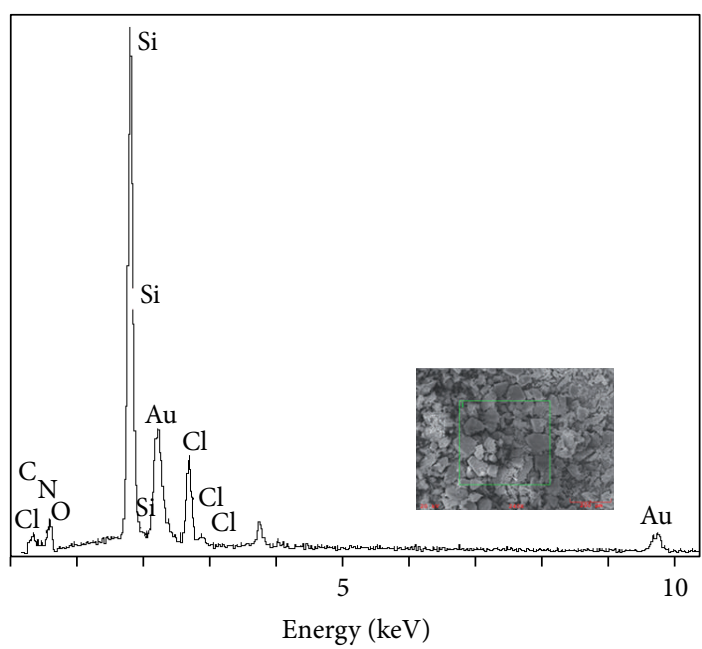

(a)

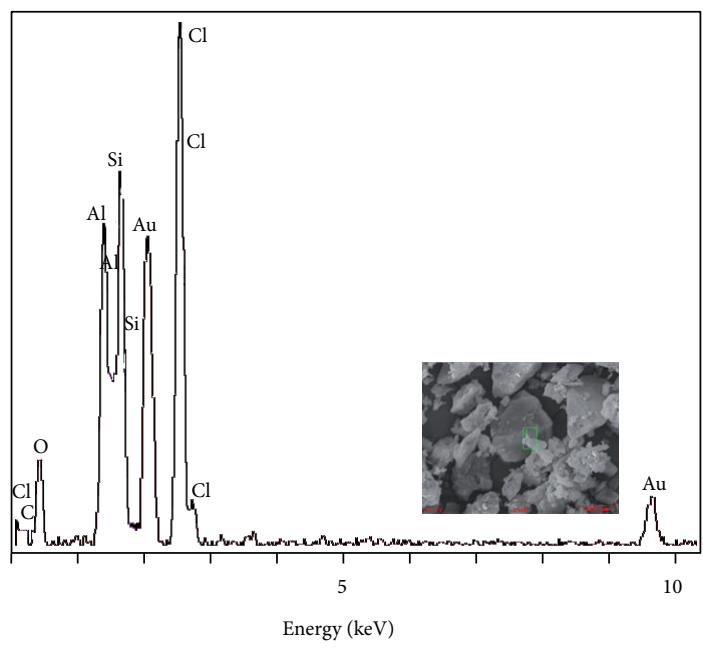

(b)

\begin{tabular}{|c|c|c|c|}
\hline Elt. & Line & $\begin{array}{c}\text { Intensity } \\
(\mathrm{C} / \mathrm{S})\end{array}$ & Conc.Wt. (\%) \\
\hline $\mathrm{C}$ & $\mathrm{Ka}$ & 8.35 & 18.765 \\
\hline $\mathrm{O}$ & $\mathrm{Ka}$ & 55.06 & 27.412 \\
\hline $\mathrm{Al}$ & $\mathrm{Ka}$ & 241.67 & 12.600 \\
\hline $\mathrm{Si}$ & $\mathrm{Ka}$ & 278.56 & 15.841 \\
\hline $\mathrm{Cl}$ & $\mathrm{Ka}$ & 445.62 & 25.383 \\
\hline & & & 100 \\
\hline
\end{tabular}

FIgure 3: EDX analysis of (a) AT-silica and (b) Al/AT-silica. 


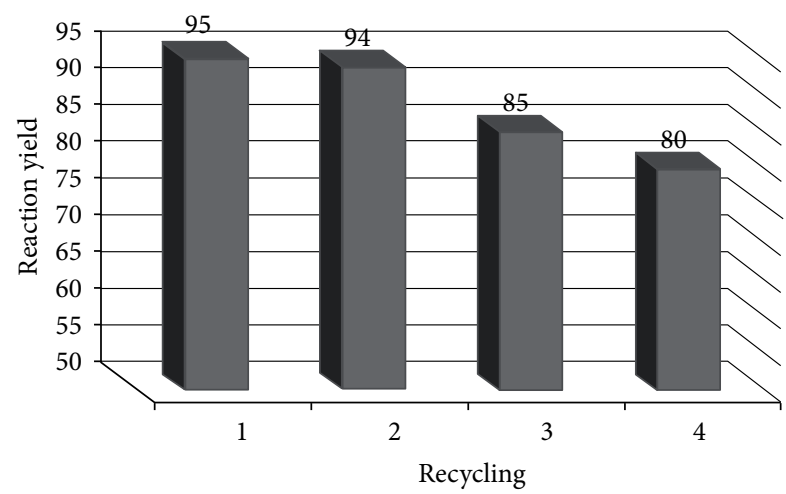

FIgURE 4: Reusability of Al/AT-silica for protection of benzyl alcohol.

tetrahydropyranylation reaction; a transformation that is difficult to accomplish via conventional methods.

\section{Conclusion}

In this study, a novel heterogeneous catalyst (Al/ATsilica) containing amino-functionalized triazine supported on silica-gel was synthesized via reaction of cyanuric chloride with silica-gel followed by treatment with ethylenediamine and coordination of aluminum chloride. This new triazine derivate was applied as a highly efficient catalyst for the tetrahydropyranylation of alcohols and phenols in the presence of DHP. In addition, this catalyst shows chemoselectivity for protection of alcohol in the mixture of alcohol and phenol. The main advantages of this catalytic system are easy catalyst preparation, mild reaction conditions, catalyst stability, easy work-up procedure, and low cost of the catalyst. In addition, it can be recycled and reused several times without loss of activity.

\section{References}

[1] A. El Maatougui, J. Azuaje, E. Sotelo, O. Caamaño, and A. Coelho, "Silica-supported aluminum chloride-assisted solution phase synthesis of pyridazinone-based antiplatelet agents," ACS Combinatorial Science, vol. 13, no. 1, pp. 7-12, 2011.

[2] S. E. Manahan, Green Chemistry and the Ten Commandments of Sustainability, ChemChar Research, Columbia, MO, USA, 2nd edition, 2006.

[3] N. C. Mehendale, C. Bezemer, C. A. van Walree, R. J. M. Klein Gebbink, and G. van Koten, "Novel silica immobilized NCNpincer palladium(II) and platinum(II) complexes: application as Lewis acid catalysts," Journal of Molecular Catalysis A, vol. 257, no. 1-2, pp. 167-175, 2006.

[4] M. Kolahdoozan, R. Javad Kalbasi, and M. Hossaini, "Synthesis of heterogeneous copper catalyst based on amino functionalized triazine rings supported by silica-gel for oxidation of alcohols," Journal of Chemistry, vol. 2013, Article ID 749723, 7 pages, 2013.

[5] K. P. Borujeni and A. R. Massah, "Synthesis and application of polystyrene supported aluminium triflate as a new polymeric
Lewis acid catalyst," Reactive \& Functional Polymers, vol. 66, no. 10, pp. 1126-1131, 2006.

[6] K. Jeyakumar and D. K. Chand, "Copper perchlorate: efficient acetylation catalyst under solvent free conditions," Journal of Molecular Catalysis A, vol. 255, no. 1-2, pp. 275-282, 2006.

[7] M. Adinolfi, G. Barone, A. Iadonisi, and M. Schiattarella, "An easy approach for the acetylation of saccharidic alcohols. Applicability for regioselective protections," Tetrahedron Letters, vol. 44, no. 25, pp. 4661-4663, 2003.

[8] A. Ghorbani-Choghamaran and N. Cheraghi-Fathabad, "Chemoselective and catalytic trimethylsilylation of alcohols and phenols by 1,1,1,3,3,3-hexamethyldisilazane and catalytic amounts of $\mathrm{PhMe}_{3} \mathrm{~N}^{+} \mathrm{Br}_{3}^{-}$," Chinese Journal of Catalysis, vol. 31, no. 9, pp. 1103-1106, 2010.

[9] H. R. Shaterian, F. Shahrekipoor, and M. Ghashang, "Silica supported perchloric acid $\left(\mathrm{HClO}_{4}-\mathrm{SiO}_{2}\right)$ : a highly efficient and reusable catalyst for the protection of hydroxyl groups using HMDS under mild and ambient conditions," Journal of Molecular Catalysis A, vol. 272, no. 1-2, pp. 142-151, 2007.

[10] M. A. Zolfigol and M. Shiri, "Molybdatophosphoric acid as a catalyst for the methoxymethylation of alcohols under solventfree conditions," Mendeleev Communications, vol. 15, no. 4, pp. 165-166, 2005.

[11] M. Moghadam, S. Tangestaninejad, V. Mirkhani, I. Mohammadpoor-Baltork, and S. Gharaati, "High-valent tin(IV) porphyrin: an efficient and reusable catalyst for tetrahydropyranylation of alcohols and phenols under mild conditions," Inorganica Chimica Acta, vol. 363, no. 7, pp. 1523-1528, 2010.

[12] A. T. Khan, E. Mondal, B. M. Borah, and S. Ghosh, "A highly efficient and chemoselective synthetic protocol for tetrahydropyranylation/depyranylation of alcohols and phenols," European Journal of Organic Chemistry, no. 21, pp. 4113-4117, 2003.

[13] B. Karimi and J. Maleki, "Lithium triflate (LiOTf) catalyzed efficient and chemoselective tetrahydropyranylation of alcohols and phenols under mild and neutral reaction conditions," Tetrahedron Letters, vol. 43, no. 30, pp. 5353-5355, 2002.

[14] M. Miyashita, A. K. Yoshikoshi, and A. P. Grieco, "Pyridinium $p$-toluenesulfonate. A mild and efficient catalyst for the tetrahydropyranylation of alcohols," Journal of Organic Chemistry, vol. 42, no. 23, pp. 3772-3774, 1977.

[15] D. M. Pore, U. V. Desai, R. B. Mane, and P. P. Wadgaonkar, "Chemoselective tetrahydropyranylation of alcohols and their detetrahydropyranylation using silicasulphuric acid as a reusable catalyst," Synthetic Communications, vol. 34, no. 12, pp. 2135-2142, 2004.

[16] K. P. Borujeni, "Silica-gel-supported aluminium chloride: a stable, efficient, selective, and reusable catalyst for tetrahydropyranylation of alcohols and phenols," Synthetic Communications, vol. 36, no. 18, pp. 2705-2710, 2006.

[17] B. Tamami and K. Parvanak Borujeny, "Chemoselective tetrahydropyranylation of alcohols and phenols using polystyrene supported aluminium chloride as a catalyst," Tetrahedron Letters, vol. 45, no. 4, pp. 715-718, 2004.

[18] G. Bartoli, R. Giovannini, A. Giuliani et al., "Solvent-free carbon-oxygen bond formation catalysed by $\mathrm{CeCl}_{3} \cdot 7 \mathrm{H}_{2} \mathrm{O} / \mathrm{NaI}$ : tetrahydropyranylation of hydroxy groups," European Journal of Organic Chemistry, no. 6, pp. 1476-1482, 2006.

[19] M. Wang, Z. G. Song, H. Gong, and H. Jiang, "Copper nitrate/acetic acid as an efficient synergistic catalytic system for the chemoselective tetrahydropyranylation of alcohols and 
phenols," Monatshefte fur Chemie, vol. 140, no. 2, pp. 177-179, 2009.

[20] G. P. Romanelli, G. Baronetti, H. J. Thomas, and J. C. Autino, "Efficient method for tetrahydropyranylation/depyranylation of phenols and alcohols using a solid acid catalyst with WellsDawson structure," Tetrahedron Letters, vol. 43, no. 42, pp. 7589-7591, 2002.

[21] Y. J. Kim and R. S. Varma, "Microwave-assisted preparation of imidazolium-based tetrachloroindate(III) and their application in the tetrahydropyranylation of alcohols," Tetrahedron Letters, vol. 46, no. 9, pp. 1467-1469, 2005.

[22] B. M. Choudary, V. Neeraja, and M. L. Kantam, "Vanadyl(IV) acetate: a mild and efficient heterogeneous catalyst for the tetrahydropyranylation of alcohols, thiols and phenols," Journal of Molecular Catalysis A, vol. 175, no. 1-2, pp. 169-172, 2001.

[23] A. R. Hajipour and F. Rafiee, "Brönsted acidic ionic liquid $\left([\mathrm{Hmim}]\left[\mathrm{HSO}_{4}\right]\right)$ as a green, efficient and reusable catalyst for the tetrahydropyranylation of alcohols," Iranian Journal of Catalysis, vol. 2, pp. 23-26, 2012.

[24] A. T. Khan, T. Parvin, and L. H. Choudhury, "Silica-supported perchloric acid $\left(\mathrm{HClO}_{4}-\mathrm{SiO}_{2}\right)$ : a versatile catalyst for tetrahydropyranylation, oxathioacetalization and thioacetalization," Synthesis, no. 15, pp. 2497-2502, 2006.

[25] M. Wang, Z. G. Song, H. Gong, and H. Jiang, "Copper methanesulfonate-acetic acid as a novel catalytic system for tetrahydropyranylation of alcohols and phenols," Chinese Chemical Letters, vol. 18, no. 7, pp. 799-802, 2007. 

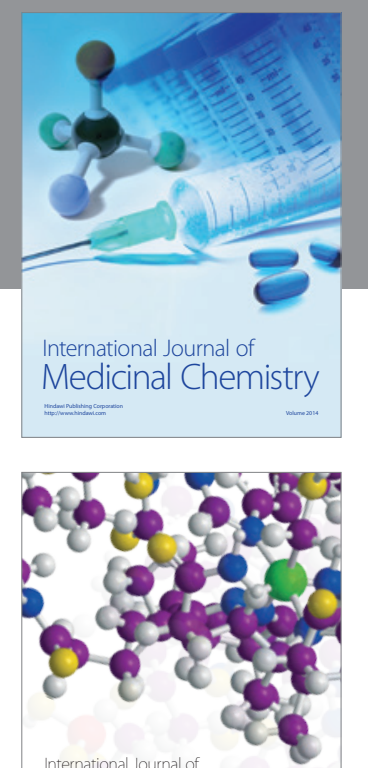

\section{Carbohydrate} Chemistry

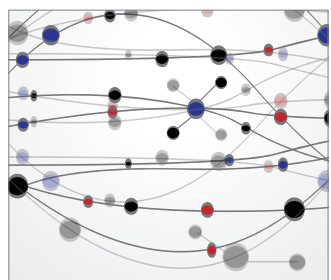

The Scientific World Journal
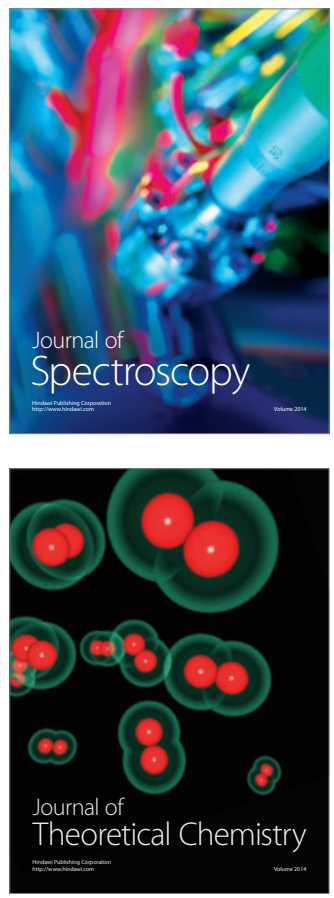
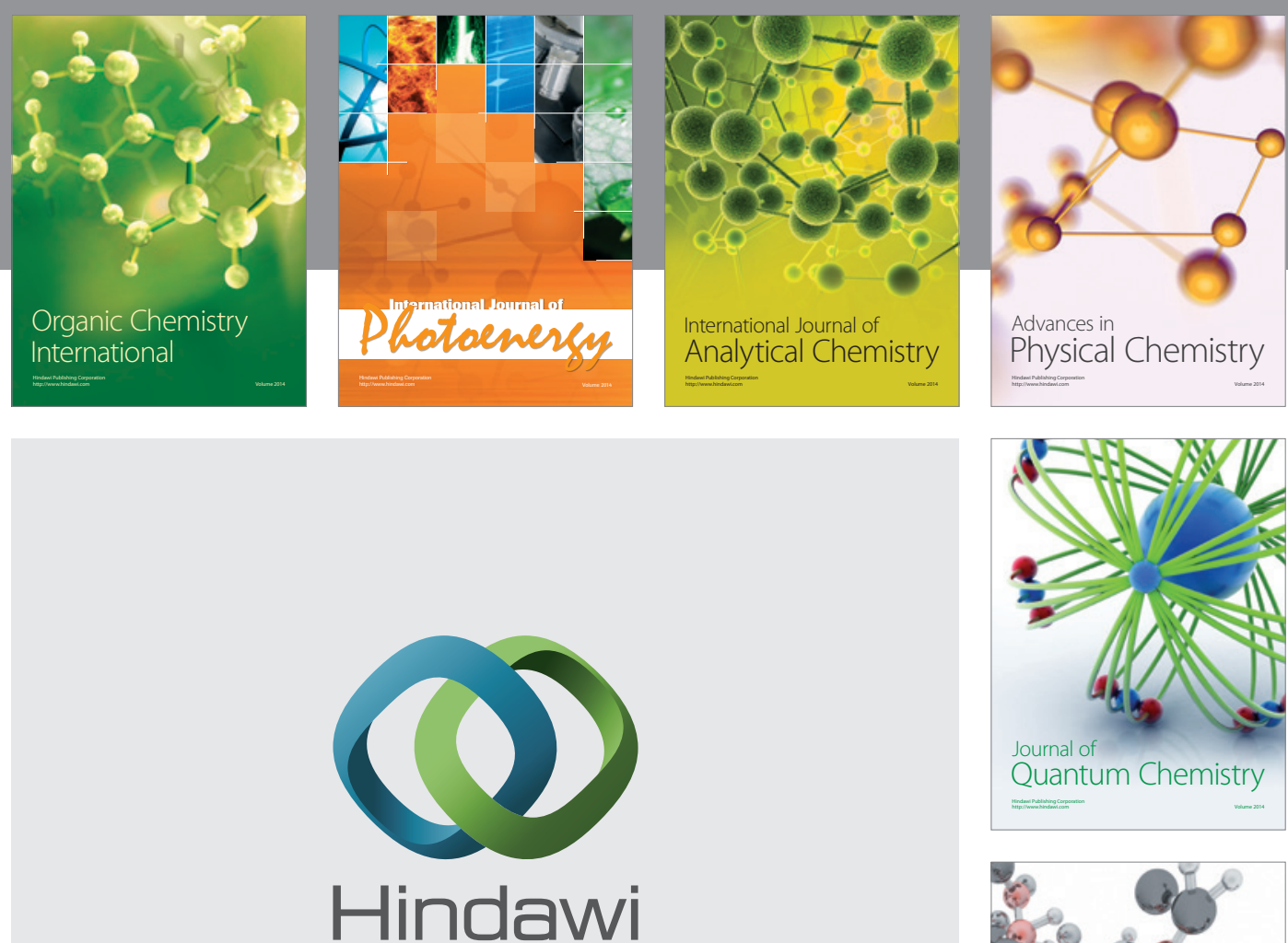

Submit your manuscripts at

http://www.hindawi.com

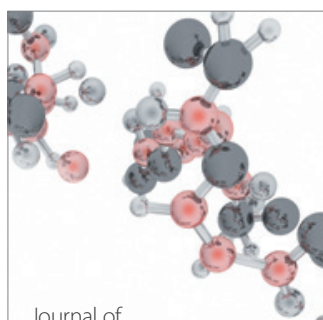

Analytical Methods

in Chemistry

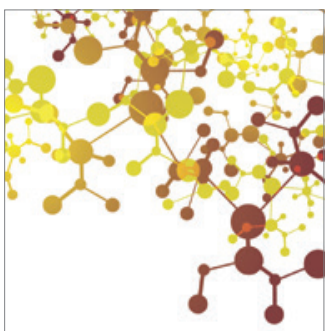

Journal of

Applied Chemistry

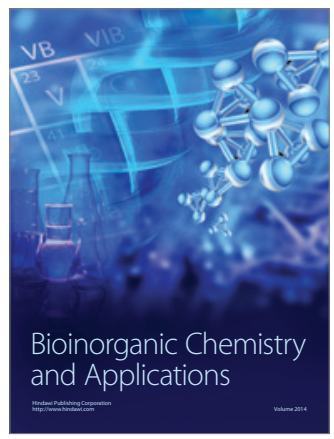

Inorganic Chemistry
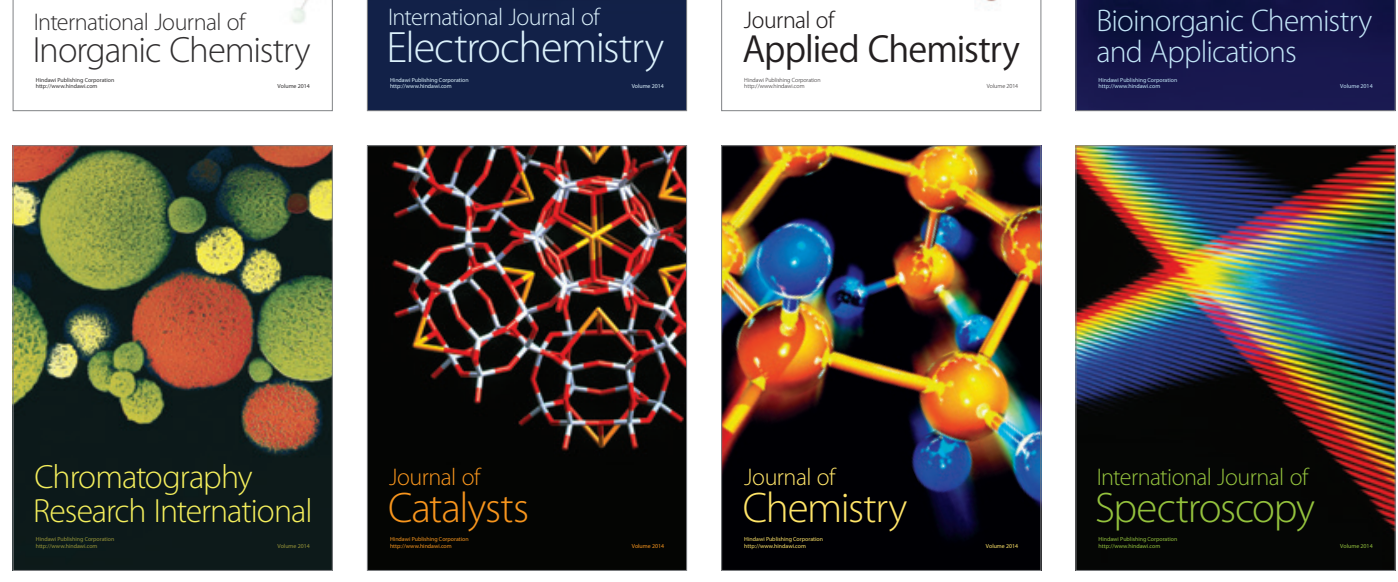